\title{
Technological Pedagogical Content Knowledge (TPACK): Kerangka Pengetahuan Guru Abad 21
}

\author{
Imam Fitri Rahmadi ${ }^{a, 1 *}$ \\ aProgram Studi Pendidikan Pancasila dan Kewarganegaraan, \\ Fakultas Keguruan dan Ilmu Pendidikan, Universitas Pamulang, Tangerang Selatan \\ Iimamrahmadi@unpam.ac.id \\ *korespondensi penulis
}

Naskah diterima: 28-01-19, direvisi: 23-02-19, disetujui: 25-03-19

DOI: http://dx.doi.org/10.32493/jpkn.v6i1.y2019.p65-74

\begin{abstract}
Abstrak
Guru abad 21 harus memiliki pengetahuan sekaligus keterampilan dalam menggunakan berbagai perangkat teknologi baik yang tradisional maupun modern untuk memfasilitasi belajar dan meningkatkan hasil pembelajaran. Artikel ini bertujuan untuk mendefinisikan, menjelaskan tentang pengukuran, dan menjelaskan tentang pengembangan technological pedagogical content knowledge (TPACK). Penulisan artikel menggunakan metode kajian pustaka dari buku, artikel jurnal, dan dokumen lain yang berkaitan dengan topik pembahasan. Hasil kajian mendapati bahwa, TPACK merupakan salah suatu jenis pengetahuan baru yang harus dikuasi guru untuk dapat mengintegrasikan teknologi dengan baik dalam pembelajaran, pengukuran TPACK merupakan aktivitas penilaian tingkat penguasaan TPACK yang dilakukan menggunakan TPACK framework, dan pengembangan TPACK merupakan kelanjutan dari proses pengukuran yang dilakukan untuk meningkatkan penguasaan TPACK. TPACK dapat dijadikan sebagai kerangka kerja untuk mendesain kurikulum pendidikan guru yang lebih sesuai dengan era dan tuntutan pembelajaran Abad 21.
\end{abstract}

Kata-kata kunci: pendidikan guru; pengetahuan guru; technological pedagogical content knowledge (TPACK)

\section{Abstract}

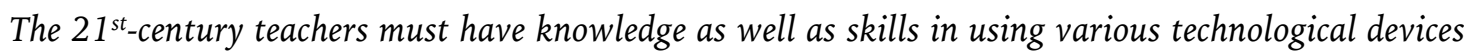
both traditional and modern to facilitate learning and improve learning performances. This article aimed at defining, explaining the measurement, and explaining the development of technological pedagogical content knowledge (TPACK). This is a literature-based article taken from books, journal articles, and other documents related to the discussed topic. The results found that TPACK is a kind of new knowledge that must be mastered by teachers to be able to integrate technology appropriately in learning and instructional processes, TPACK measurement is a TPACK confidence level assessment activity carried out using the TPACK framework, and TPACK development is a continuation of the measurement process carried out to increase the TPACK confidence. TPACK could be used as a framework for designing teacher education curricula that is more in line with the era and demands of $21^{\text {st-century learning. }}$

Keywords: teacher education; teachers' knowledge; technological pedagogical content knowledge (TPACK) 


\section{Pendahuluan}

Para guru abad 21 tidak cukup hanya memiliki pengetahuan tentang materi yang diajarkan dan cara mengajarkannya. Perkembangan ilmu pengetahuan, teknologi, dan seni terkini dalam bidang pendidikan, menuntut guru untuk juga memiliki pengetahuan tentang teknologi dan penggunaannya dalam belajar dan pembelajaran. Guru abad 21 harus memiliki pengetahuan sekaligus keterampilan dalam menggunakan berbagai perangkat teknologi baik yang tradisional maupun modern untuk memfasilitasi belajar dan meningkatkan hasil pembelajaran.

Mengajar merupakan aktivitas kompleks yang melibatkan berbagai jenis pengetahuan. Aktivitas mengajar didasari dengan pengetahuan tentang materi yang akan diajarkan (content knowledge), cara mengajarkan suatu materi (pedagogical knowledge), dan pengetahuan tentang penggunaan berbagai teknologi (technological knowledge) yang ketiganya memiliki persinggungan untuk dapat mendukung satu di antara lainnya (Mishra \& Koehler, 2006). Teori lama yang menyatakan bahwa dalam mengajar dibutuhkan pengetahuan tentang konten dan pedagogik serta pengetahuan hasil persinggungan keduanya yaitu pedagogical content knowledge (Shulman, 1986) sudah tidak relevan lagi untuk dipalikasikan pada era pembelajaran abad 21 .

Pembelajaran pada abad 21 mengintegrasikan berbagai perangkat teknologi dalam melakukan selutuh rangkaian proses interaksi antara siswa dan guru dengan sumber belajar dalam suatu lingkungan belajar. Teknologi berperan aktif sebagai alat, proses, dan sekaligus sumber untuk belajar dan melaksanakan pembelajaran (Partnership for 21 Century Learning, 2007). Maka, siswa dan guru pada abad 21 harus memiliki literasi teknologi yang memada (Drew, 2012; Kereluik, Mishra, Fahnoe, \& Terry, 2013; Trust, 2018). Terlebih, para calon guru masa depan harus dipastikan memiliki pengetahuan, keterampilan dan kompetensi teknologi yang baik, supaya dapat mengintegrasikan teknologi dalam pembelajaran dengan efektif dan efisien (Koehler \& Mishra, 2005: 94; Guzman \& Nussbaum, 2009; Koehler dkk., 2011: 149).

Sangat disayangkan isu tentang literasi teknologi bagi guru masa depan belum direspon dengan serius oleh para pemangku kebijakan. Landasan revitalisasi Lembaga Pendidikan Tenaga Kependidikan (LPTK) sebagai lembaga yang menghasilkan para calon guru (Kementerian Riset Teknologi dan Pendidikan Tinggi, 2015), pengembangan kurikulum LPTK (Asosiasi Lembaga Pendidikan Tenaga Kependidikan Indonesia, 2016), dan desain kurikulum Pendidikan Profesi Guru (Direktoran Jenderal Pembelajaran dan Mahasiswa, 2017) masih menggunakan teori lama, yaitu subject-spesific pedagogy milik McDiarmid \& Ball (1989) atau dalam teori yang dikemukakan Shulman (1986) disebut sebagai pedagogical content knowledge (PCK).

Artikel ini bertujuan untuk mengulas teori terbaru tentang pengetahuan guru, yaitu technological pedagogical content 
knowledge (TPACK), sebuah kerangka pengetahuan guru yang sangat relevan untuk diaplikasikan pada abad 21. Pembahasan dimulai dengan mendefinisikan apa itu TPACK, menjelaskan tentang pengukuran TPACK, dan menjelaskan tentang pengembangan TPACK.

\section{Metode}

Artikel ini ditulis menggunakan metode kajian pustaka. Kepustakaan yang digunakan terdiri dari buku, artikel jurnal, dan dokumen lain yang berkaitan dengan topik pembahasan. Pustaka yang digunakan merupakan pustaka terbaru terbitan 10 tahun terakhir. Kajian dalam artikel lebih menitikberatkan pada analisis artikel jurnal terbaru yang berkaitan dengan TPACK. Buku dan dokumen lainnya, hanya dijadikan pendukung untuk melengkapi informasi yang tidak ditemukan pada artikel jurnal. Penulisan artikel menggunakan standar penulisan akademik dalam Bahasa Indonesia supaya mudah dipahami oleh insan akademik pembaca artikel.

\section{Pembahasan}

Sesuai dengan tujuan penulisan artikel, pembahasan dalam artikel ini, meliputi; 1) apa itu TPACK?; 2) pengukuran TPACK; 3) pengembangan TPACK. Ketiga topik tersebut dibahas secara deskriptif kritis menggunakan referensi dari berbagai sumber terbaru. Referensi yang digunakan, khususnya dari artikel jurnal, didukung dengan referensi dari buku dan dokumen lain yang relevan dengan pembahasan. Pembahasan dalam artikel ini menyuguhkan penjelasan terkait dengan TPACK dan menyajikan ide penggunaan TPACK untuk kurikulum pendidikan guru.

\section{Apa itu TPACK?}

Technological pedagogical content knowledge (TPACK) merupakan salah suatu jenis pengetahuan baru yang harus dikuasi guru untuk dapat mengintegrasikan teknologi dengan baik dalam pembelajaran (Mishra \& Koehler, 2006). Pada perkembangannya, TPACK telah menjadi kerangka kerja atau framework yang dapat digunakan untuk menganalisis pengetahuan guru terkait dengan integrasi teknologi dalam pembelajaran (Koehler \& Mishra, 2009: 62; Cox \& Graham, 2009; Koehler, Mishra, \& Cain, 2013: 14). Berikut ini gambaran TPACK framework. 


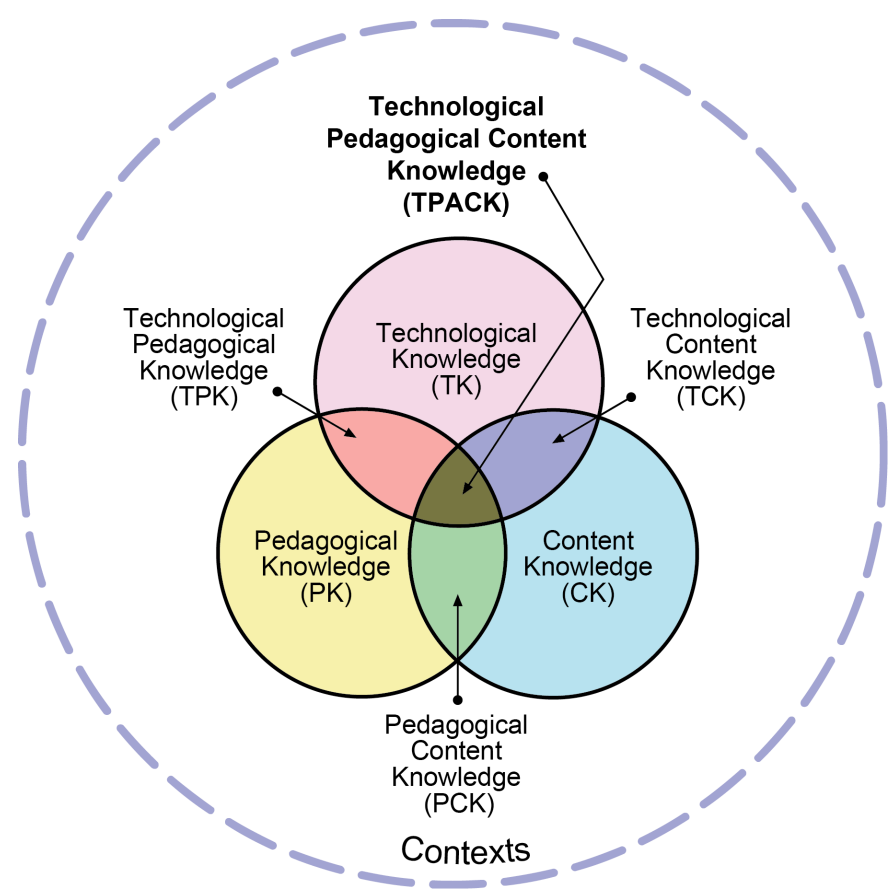

Gambar 1. Technological Pedagogical Content Knowledge (TPACK) Framework (Mishra \& Koehler, 2008)

TPACK terbentuk atas perpaduan 3 jenis pengetahuan dasar, yaitu Technological Knowledge (TK), Pedagogical Knowledge (PK), Content Knowledge (CK). Hasil perpaduan 3 pengetahuan dasar tersebut, menghasilkan 4 pengetahuan baru, meliputi Pedagogical Content Knowledge (PCK), Technological Content Knowledge (TCK), Technological Pedagogical Knowledge (TPK), dan Technological Pedagogical Content Knowledge (TPACK). Gambar di atas dengan jelas memperlihatkan interelasi antara 3 pengetahuan dasar yang mengahasilkan 4 pengetahuan. Berikut ini penjelasan setiap domain pengetahuan TPACK yang disarikan dari Mishra \& Koehler (2006 \& 2008), Koehler \& Mishra (2009) dan Koehler, Mishra, \& Cain (2013).

Technological knowledge (TK) atau pengetahuan teknologi merupakan pengetahuan tentang berbagai jenis teknologi sebagai alat, proses, maupun sumber. Pedagogical knowledge (PK) atau pengetahuan pedagogik yaitu pengetahuan tentang teori dan praktik dalam perencanaan, proses, dan evaluasi pembelajaran. Content knowledge (CK) atau pengetahuan konten adalah pengetahuan tentang konten atau materi pelajaran yang harus dipelajari oleh guru dan diajarkan kepada siswa.

Pedagogical content knowledge (PCK) atau pengetahuan pedagogik konten merupakan pengetahuan pedagogik yang berhubungan dengan konten khusus (Shulman, 1986). Technological content knowledge (TCK) atau pengetahuan teknologi konten adalah pengetahuan tentang timbal balik antara teknologi dengan konten. Technological pedagogical knowledge (TPK) atau pengetahuan teknologi pedagogik adalah pengetahuan tentang berbagai teknologi dapat 
digunakan untuk memfasilitasi belajar dan pembelajaran.

Technological Pedagogical Content Knowledge (TPACK) atau pengetahuan teknologi pedagogik dan konten adalah pengetahuan tentang penggunaan teknologi yang tepat pada pedagogik yang sesuai untuk mengajarkan suatu konten dengan baik. Ketujuh pengetahuan tersebut perlu dikuasai oleh calon guru masa depan yang akan mengajar dalam lingkungan belajar yang dipenuhi dengan berbagai instrumen teknologi. Supaya guru dapat menggunakan teknologi yang tepat pada pedagogik yang sesuai untuk konten yang spesifik dengan baik.

\section{Pengukuran TPACK}

Pengukuran TPACK merupakan aktivitas penilaian tingkat penguasaan TPACK yang dilakukan menggunakan TPACK framework. Pengukuran ini lazim dilakukan kepada para pendidik dan pelatihan seperti guru, dosen, tutor, instruktur, dan lainnya dalam seting pendidikan formal, informal maupun non formal. Pada pengukuran dilihat tingkat penguasaan TPACK seseorang dengan kaitannya dalam kemampuan untuk dapat melakukan integrasi teknologi dalam belajar dan pembelajaran yang dilakukan (Koehler \& Mishra, 2009: 67).

Setidaknya, terdapat 3 manfaat yang didapat ketika melakukan pengukuran TPACK (Koehler, Mishra, \& Cain, 2013: 17). Pertama, melalui pengukuran TPACK didapati profil penguasaan TPACK yang dapat menunggambarkan tingkat pengkat penguasaan pada setiap domain pengetahuan. Kedua, pengukuran TPACK dapat menjadi refleksi dalam penyelenggaraan pendidikan bagi calon guru. Ketiga, menentukan dampak intervensi pembelajaran terkait integrasi teknologi yang diberikan kepada calon guru ketika menempuh pendidikan guru.

Pengukuran TPACK dapat dilakukan dengan berbagai cara baik secara kuantitatif maupun kualitatif. Pada umumnya, terdapat 5 cara yang dapat dilakukan untuk melakukan pengukuran TPACK, yaitu; 1) self report-measure; 2) open-ended questionnaire; 3) performance assessment; 4) interview; dan 5) observation (Abbit, 2011; Koehler, Shin, \& Mishra, 2012: 21). Metode pengukuran dipilih salah satu atau menggabung beberapa metode tersebut. Konteks masing-masing penelitian yang menjadi pertimbangan dalam pemilihan metode pengukuran.

Self report-measure merupakan metode yang meminta responden untuk memilih tingkat kesesuaian suatu penyataan dengan kondisi nyata yang terjadi pada diri responden. Open-ended questionnaire merupakan metode yang berisi pertanyaan terbuka ditujukan kepada responden untuk dapat dijawab secara tertulis. Performance assessment merupakan metode yang mengevaluasi tingkat penguasaan TPACK berdasarkan penampilan langsung yang dilakukan oleh responden. Interview merupakan metode yang berisi serangkaian pertanyaan yang ditujukan kepada responden untuk dijawab secara lisan. Observation merupakan metode yang mengamati perubahan nyata yang terjadi pada responden melalui perekaman video atau catatan lapangan. 
Pengukuran TPACK harus spesifik pada satu konten tertentu. Tingkat penguasaan TPACK secara keseluruhan sangat erat kaitannya dengan konten. Maka, pengukurannya harus berfokus pada satu konten tertentu, misalkan matematika, IPA, IPS, Bahasa, dan yang lainnya. Selain itu, pengukuran TPACK dapat dilakukan pada guru prajabatan maupun guru dalam jabatan. Penggunaan metode pengukuran dapat disesuaikan dengan kebutuhan dan tujuan kedalaman pengukuran. Penggabungan beberapa metode pengukuran dapat memperdalam sekaligus memperluas hasil yang didapatkan.

Pengukuran TPACK pada berbagai konten telah dilakukan oleh para peneliti di luar negeri pada program studi bahasa inggris (Baser, Kopcha, \& Ozden, 2016), ekonomi (Raman, 2014), Ilmu Pengetahuan Alam - IPA (Jang \& Tsai, 2012; Maeng, Mulvey, Smetana, \& Bell, 2013; Canbazoglu Bilici, Guzey, \& Yamak, 2016), matematika (Jang \& Tsai, 2012; Cuhadar, 2018) dan Ilmu Pengetahuan Sosial - IPS (Cuhadar, 2018). Pengukuran TPACK di Indonesia telah dilakukan pada program studi matematika (Listiawan \& Baskoro, 2015), biologi (Agustina, Sundari, \& Ardani, 2016; Dhawati, 2017; Dhawati \& Hariyatmi, 2017; Sukaesih, Ridlo, \& Saptono, 2017; Fathonah, 2017; Agustina, Yusron, \& Muyassarah, 2018) dan fisika (Sholihah, 2016; Yuliati \& Wartono, 2016; Khoiri \& Huda, 2017). Pengukuran mendapatkan hasil yang berbeda-beda terutama pada konten dengan karakteristik yang bertolak belakang. Hal ini memperlihatkan bahwa konten sangat mempengaruhi hasil pengukuran TPACK.

\section{Pengembangan TPACK}

Pengembangan merupakan kelanjutan dari proses pengukuran TPACK. Pengukuran dilakukan untuk mengetahuai tingkat penguasaan, sedangkan pengembangan dilakukan untuk meningkatkan penguasaan TPACK (Sim, Finger, \& Smart, 2016). Peningkatan penguasaan ditekankan pada domain pengetahuan TPACK yang masih lemah. Berbagai cara dapat dilakukan untuk mengembangkan TPACK, meliputi; 1) mengikuti perkuliahan terkait teknologi pendidikan; 2) menggunakan strategi pembelajaran yang menjadi bagian dari perkuliahan; dan 3) mengunakan strategi pembelajaran dalam keseluruhan program pendidikan guru (Mouza, 2016: 176).

Perkuliahan terkait teknologi pendidikan membekali kemampuan dalam mendesain, mengembangkan, memanfaatkan, menggunakan, mengelola, dan mengevaluasi pembelajaran menggunakan berbagai teknologi sebagai proses, alat, maupul sumber dalam belajar. Penggunaan strategi pembelajaran yang menjadi bagian dari perkuliahan, merupakan upaya mengintegrasikan pengembangan TPACK dalam suatu perkuliah yang berkaitan dengan konten. Penggunaan strategi pembelajaran dalam keseluruhan program pendidikan guru, merupakan langkah integrasi TPACK secara lebih komprehensif dalam kurikulum pendidikan guru.

Pengembangan TPACK juga harus dilakukan pada satu konten yang spesifik. 
Pengembangannya akan kurang maksimal jika menggabungkan berbagai konten. Pemilihan metode pengembangan TPACK disesuaikan dengan kebutuhan, tujuan, dan konteks masing-masing. Pengembangan TPACK lazim dilakukan dalam suatu penelitian dan pengembangan yang berkelanjutan, dimulai dengan pengukuran TPACK terlebih dulu, kemudian baru dilakukan pengembangannya.

\section{Kesimpulan}

TPACK merupakan salah suatu jenis pengetahuan baru yang harus dikuasi guru untuk dapat mengintegrasikan teknologi dengan baik dalam pembelajaran. Selain menjadi suatu jenis pengetahuan baru, TPACK telah menjadi kerangka kerja atau framework yang dapat digunakan untuk menganalisis pengetahuan guru terkait dengan integrasi teknologi dalam pembelajaran. Pengukuran TPACK merupakan aktivitas penilaian tingkat penguasaan TPACK yang dilakukan menggunakan TPACK framework. Pengembangan TPACK merupakan kelanjutan dari proses pengukuran yang dilakukan untuk meningkatkan penguasaan TPACK. TPACK dapat dijadikan sebagai kerangka kerja untuk mendesain kurikulum pendidikan guru yang lebih sesuai dengan era dan tuntutan pembelajaran Abad 21.

\section{Referensi}

Abbitt, J. T. (2011). Measuring technological pedagogical content knowledge in preservice teacher education: A review of current methods and instruments. Journal of
Research on Technology in Education, 43(4), 281-300.

Agustina, P., Yusron, F. N., \& Muyassarah, F. (2018). Pedagogical Content Knowledge (PCK) Mahasiswa Calon Guru Biologi FKIP UMS pada Matakuliah Microteaching Tahun Akademik 2015/2016. Proceeding of The URECOL, 101-108.

Agustina, P., Yusron, F. N., \& Muyassarah, F. (2018). Pedagogical Content Knowledge (PCK) Mahasiswa Calon Guru Biologi FKIP UMS pada Matakuliah Microteaching Tahun Akademik 2015/2016. Proceeding of The URECOL, 101-108.

Asosiasi Lembaga Pendidikan Tenaga Kependidikan Indonesia. (2016). Proposal Penyusunan Pedoman Pengembangan Kurikulum Lembaga Pendidikan Tenaga Kependidikan (LPTK). Jakarta: ALPTKI.

Baser, D., Kopcha, T. J., \& Ozden, M. Y. (2016). Developing a technological pedagogical content knowledge (TPACK) assessment for preservice teachers learning to teach English as a foreign language. Computer Assisted Language Learning, 29(4), 749-764. https://doi.org/10.1080/09588221.20 $\underline{15.1047456}$

Canbazoglu Bilici, S., Guzey, S. S., \& Yamak, H. (2016). Assessing preservice science teachers' technological pedagogical content knowledge (TPACK) through observations and lesson plans. Research in Science $\mathcal{E}$ Technological Education, 34(2), 237251.

https://doi.org/10.1080/02635143.20 $\underline{16.1144050}$ 
Cox, S., \& Graham, C. R. (2009). Using an elaborated model of the TPACK framework to analyze and depict teacher knowledge. TechTrends, 53(5), 60-69.

Cuhadar, C. (2018). Investigation of PreService Teachers' Levels of Readiness to Technology Integration in Education. Contemporary Educational Technology, 9(1), 61-75.

Dhawati, D. A. A. (2017). Kemampuan Technological Pedagogical Content Knowledge (TPACK) Calon Guru Biologi Fkip Ums Dalam Menyusun Rpp Kurikulum 2013 Tahun Akademik 2016/2017 (Doctoral dissertation, Universitas Muhammadiyah Surakarta).

Direktoran Jenderal Pembelajaran dan Mahasiswa. (2017). Pedoman Penyelenggaraan Pendidikan Profesi Guru. Jakarta: Dirjen Belmawa.

Direktorat Riset dan Pengabdian Masyarakat. (2018). Panduan penelitian dan pengabdian kepada masyarakat edisi XII tahun 2018. Jakarta: Kemenristekdikti.

Drew, S. V. (2012). Open up the ceiling on the Common Core State Standards: Preparing students for 21 st-century literacy-now. Journal of Adolescent \& Adult Literacy, 56(4), 321330.

Fathonah, L. (2017). Kemampuan TPACK (Technological Paedagogical and Content Knowledge) Calon Guru Biologi FKIP UMS dalam Menyusun Rencana Pelaksanaan Pembelajaran Kurikulum 2013 Tahun Akademik 2016/2017(Doctoral dissertation, Universitas Muhammadiyah Surakarta).
Framework for 21st Century Learning P21. (t.t.). Diambil 4 Agustus 2018, dari http://www.p21.org/ourwork/p21-framework

Guzman, A., \& Nussbaum, M. (2009). Teaching competencies for technology integration in the classroom: Technology integration in the classroom. Journal of Computer Assisted Learning, 25(5), 453-469. https://doi.org/10.1111/j.13652729.2009.00322. $\mathrm{x}$

Jang, S.-J., \& Tsai, M.-F. (2012). Exploring the TPACK of Taiwanese elementary mathematics and science teachers with respect to use of interactive whiteboards. Computers \& Education, $59(2)$, 327-338. https://doi.org/10.1016/j.compedu.2 012.02 .003

Kementerian Riset Teknologi dan Pendidikan Tinggi. (2015). Naskah Akademik Revitalisasi Lembaga Pendidikan Tenaga Kependidikan (LPTK). Jakarta: Kemensirtekdikti.

Kereluik, K., Mishra, P., Fahnoe, C., \& Terry, L. (2013). What knowledge is of most worth: Teacher knowledge for 21 st century learning. Journal of Digital Learning in Teacher Education, 29(4), 127-140.

Khoiri, N., \& Huda, C. (2017). Deskripsi Technological Pedagogical Content Knowledge (TPACK) Pada Mahasiswa Calon Guru Fisika.

Koehler, M. J., \& Mishra, P. (2005). Teachers learning technology by design. Journal of computing in teacher education, 21 (3), 94-102.

Koehler, M. J., Mishra, P., \& Cain, W. (2013). What is technological pedagogical content knowledge 
(TPACK)?. Journal

Education, 193(3), 13-19.

Koehler, M. J., Mishra, P., Bouck, E. C., DeSchryver, M., Kereluik, K., Shin, T. S., \& Wolf, L. G. (2011). Deep-play: Developing TPACK for 21st century teachers. International Journal of Learning Technology, 6(2), 146-163.

Koehler, M., \& Mishra, P. (2009). What is technological pedagogical content knowledge (TPACK)?. Contemporary issues in technology and teacher education, 9(1), 60-70.

Listiawan, T., \& Baskoro, W. W. (2015). Analisis Technological Content Knowledge (TCK) Calon Guru Matematika Dalam Menggunakan Perangkat Lunak Geometri Dinamis. In Prosiding Seminar Nasional Matematika Dan Pendidikan Matematika UNY (pp. 827-834).

Maeng, J., Mulvey, B., Smetana, L., \& Bell, R. (2013). Preservice Teachers' TPACK: Using Technology to Support Inquiry Instruction. Journal of Science Education and Technology, 22(6), 838857.

McDiarmid, G. W., \& Ball, D. L. (t.t.). Anderson, C. W.(1989)'Why Staying One Chapter Ahead Doesn't Really Work: Subject-Specific Pedagogy.'. Knowledge base for the beginning teacher, 193-205.

Mishra, P., \& Koehler, M. J. (2006). Technological pedagogical content knowledge: A framework for teacher knowledge. Teachers college record, $108(6), 1017$.

Mishra, P., \& Koehler, M. J. (2008). Introducing TPCK. AACTE Committee on Innovation and Technology. The handbook of technological pedagogical content knowledge (TPCK) for educators (pp. 3-29). Mahwah, NJ: Lawrence Erlbaum Associates.

Mouza, C. (2016). Developing and assessing TPACK among pre-service teachers. Handbook of technological pedagogical content knowledge (TPACK) for educators, 169.

Raman, A. (2014). TPACK Confidence of Pre-service Teachers in Universiti Utara Malaysia. Mediterranean Journal of Social

Sciences. https://doi.org/10.5901/mjss.2014.v5 n22p167

Sahin, I. (2011). Development of survey of technological pedagogical and content knowledge (TPACK). Turkish Online Journal of Educational TechnologyTOJET, 10(1), 97-105.

Schmidt, D. A., Baran, E., Thompson, A. D., Mishra, P., Koehler, M. J., \& Shin, T. S. (2009). Technological pedagogical content knowledge (TPACK) the development and validation of an assessment instrument for preservice teachers.Journal of research on Technology in Education, 42(2), 123149.

Sholihah, M. A. (2016). Technological Pedagogical Content Knowledge dan Kemampuan Menyusun Perangkat Pembelajaran Calon Guru Fisika melalui Model Pembelajaran POSTPACK di Universitas Negeri Malang. DISERTASI dan TESIS Program Pascasarjana UM.

Shulman, L. S. (1986). Those who understand: Knowledge growth in teaching. Educational researcher, 15(2), 4-14. 
Jurnal Pendidikan Kewarganegaraan

Vol. 6 No. 1 Maret 2019

Sim, C., Finger, G., \& Smart, V. (2016). 4Developing TPACK: Envisioning Technological Pedagogical Reasoning. Dalam Handbook of technological pedagogical content knowledge (TPACK) for educators (hlm. 63-72). Routledge.

Sukaesih, S., Ridlo, S., \& Saptono, S. (2017). Analisis Kemampuan Technological Pedagogical And Content Knowledge (TPACK) Calon Guru Pada Mata Kuliah PP Bio. In Prosiding SNPS (Seminar Nasional Pendidikan Sains) (pp. 58-64).

Trust, T. (2018). 2017 ISTE Standards for Educators: From Teaching With
Journal of Civics and Education Studies p-ISSN 2302-0865 | e-ISSN 2621-346X

Technology to Using Technology to Empower Learners. Journal of Digital Learning in Teacher Education, 34(1), 13.

https://doi.org/10.1080/21532974.20 17.1398980

Yuliati, L., \& Wartono, W. (2016). Peranan TPACK terhadap Kemampuan Menyusun Perangkat Pembelajaran Calon Guru Fisika dalam Pembelajaran Post-Pack. Jurnal Pendidikan: Teori, Penelitian, dan Pengembangan, 1(2), 144-153. 